contained in my edition of Lummer's book--slips for which I take the entire responsibility. The error on p. 100 in supposing that the Munich view was photographed by Prof. Miethe, of Berlin, arose from a confusion between two sets of telephotographic views sent me from Germany, some of which were taken by Prof. Miethe. I would point out that, in the only case in which the kind of lens used is stated, it is correctly stated to be a Steinheil's lens. I presume Dr. Steinheil is not dissatisfied with the performance of the lens in producing the picture, by whomsoever it was photographed. The other point arose from inserting at the last moment, when the sheets were going to press, a reference to Messrs. R. and J. Beck, which should have been inserted at the end of paragraph four instead of paragraph three of Chapter xi. Let me assure I)r. Steinheil that both points will be corrected in any fresh issue of the text.

February 9 . Silvanits P. THOMl'son.

\section{The Ash Constituents of Some Lakeland Leaves.}

Arthougu it cannot be maintained that the amount of inorganic matter which the leaves of a tree extract from the soil on which it grows is quite independent of the chemical com. position, \&c., of that soll, it was deemed advisable to perform a few experiments bearing on this particular feature. Notwith. standing the consirlerable elevation, vi\%. about 400 feet, the soil in this locality is distinctly suited and adapted to the growth and healthy development of most of our well-known forest trees. It is a cold, basic clay, mostly not very stiff, on account of the presence of some gravel and peat in many places, and, generally speaking, enriched with considerable quantities of potash, silica and manganese, while a serious deficiency in lime is attested by the universal prevalence of distinctly calcifuge plants. The percentage of crude ash set down in the subjoined table was calculated from the combustion of the leaves gathered in the evening, dried first in the air and then at $100^{\circ} \mathrm{C}$. The details are as described :--

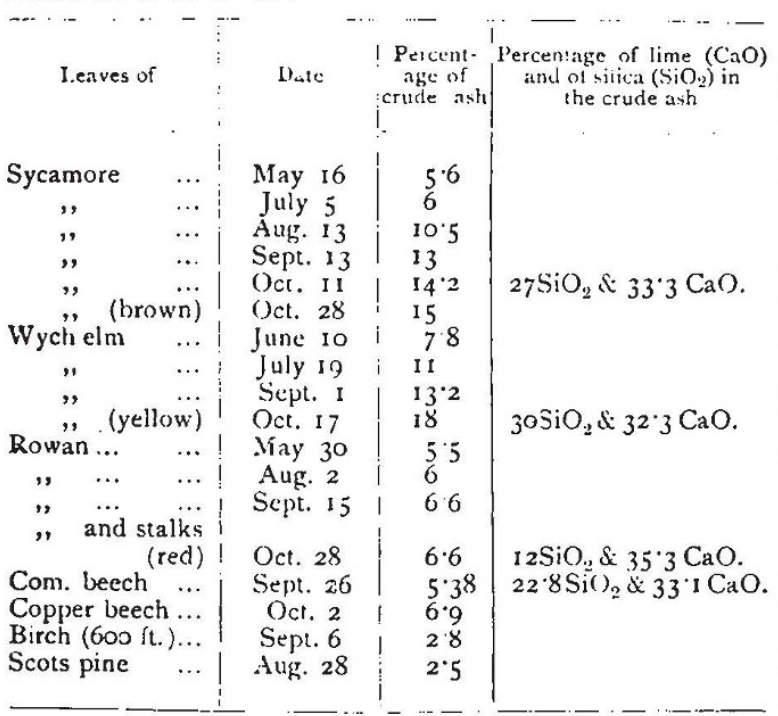

The steady increase in the quantity of ash in the leaves of sycamore and wych elm as the season progresses is here exhibited with sufficient emphasis. The peculiarity, however, is that in the case of the sycamore the percentage does not reach the figure that it might do on other soils or under other circumstances; for instance, according to Schleiden and Schmidt, it might come up to 28 per cent.; but this proportion, I make bold to say, is never attained in any part of British Lakeland. The surprisingly large percentage of silica and lime in the ash of the deep crimson leaves and petioles of the rowan demands further investigation, inasmuch as this is a rather calcifuge tree, and the amount of silica in other allied Rosaceans is very small. According to Rismuller, the ash of dry beech leaves is 4.6 per cent. on May 7 and I $\mathrm{I} \cdot 4$ per cent. on November 18 ; whereas Gueymard found that when gathered after natural fall and dried they yield only 5.6 per cent. ash, and my experi. ments do not warrant the assumption of any serious difference

No. 1634 , vOL. 63 ] as respects inorganic constituents between the vernal and autumnal foliage of this tree. "Alone among the species of the first order of . Mid and North Furope," says MM. Fliche and Grandeau, "the Scots pine seems to seek out siliceous soils, but the physical rather than the chemical conditions of the soil seem, as regards this species, to have a preponderant influence." Nevertheless, the percentage of ash in its first and second years' leaves is precisely the same here as it is in North Germany, and the extremely moderate incrganic paluulum that suffices to sustain it and the birch enables them to bear the privations of an upland abode.

Patterdale, Westmorland. P. Q. KFEGAN.

\section{An Earthquake on February 10.}

In the early hours of February 10, in the town of Grazalema, there was experienced an intense earthquake, with damages to buildings, many of them being rent.

The duration was about three seconds, and the movement a compound one of uscillation and trepidation, accompanied with considerable noise.

The people ran out of the houses fuli of terror

The church of Saint Joseph and some other large buildings have been very severely damaged, and also factories and mills.

The body of water that provided motive power for the machinery in one of the factories has disappeared.

Grazalema is a town of 10,000 inhabitants, situated in a hilly district of the province of Cadiz, at about 70 kilometres, nearly due north, from Gibraltar. Aucivsto ARCimis.

Instituto Central Mcteorologico, Madrid, February I 3.

\section{The late Prof. Hermite.}

Votr interesting memoir of Prof. Hermite differs in one detail from the account in "Men and Women of the Time." It is said there that he was born at Dieuze, in Lorraine, and that he was for a while at Nancy before going to Paris.

W. B. C.

\section{THE RADIO-ACTIVITY OF MATTER.}

$A^{T}$ the commencement of the year 1896 , in carrying A out some experiments with the salts of uranium, the exceptional optical properties of which I had been studying for some time, I observed that these salts emitted an invisible radiation, which traversed metals and bodies opaque to light as well as glass and other transparent substances. This radiation impressed a photographic plate and discharged from a distance electrified bodies - properties giving two nethods for studying the new rays.

The phenomenon does not appear to be influenced by any known external cause, such as a variation of temperature or a luminous excitation; it is entirely different from phosphorescence ; is not weakened in an appreciable manner by time, even at the end of several years; and is emitted spontaneously without any apparent exciting cause. The radiating property appeared, firstly, to be bound up with the presence of the chemical element uranium ; the metal discharges electrified bodies three to four times faster than its salts.

If some fragments of uranium or of one of its salts are placed upon a photographic plate wrapped in black paper or covered by an aluminium leaf, and if between the uranium and the plate various substances are interposed, there is obtained at the end of several hours or days, radiographs showing that the radiation is propagated in straight lines, and traverses different bodies unequally. In the radiographs the edges of the plates of glass, or of thin plates of other substances, throw a sort of shadow, which is still unexplained. This phenomenon, as well as an inequality obtained twice accidentally through parallel and crossed tourmalines, led to the belief at the commencement of these researches that these rays had properties in common with light. But all the later experiments have shown that the new radiation undergoes neither reflection, refraction nor polarisation. 
The uranium radiation dissipates with equal rapidity either positive or negative electric charges ; the effect is unequally transmitted through screens of different materials according to their nature and according to the order in which they have been simultaneously interposed. This fact leads to the prediction of the heterogeneity of the radiation. The dissipation of the charges of an electrified body submitted to the uranium radiation takes place through the action of the surrounding gas, which is thereby made conducting; the air keeps this property during some instants, and if, after having been influenced, it is blown on to an electrified body, the latter is discharged. A sphere of uranium remains charged if it is placed in a vacuum ; in air it puts itself in equilibrium as regards potential with the surrounding space. The rate of leak increases with the potential, and, for high potentials, tends to a constant.

If two conductors are arranged at some centimetres apart, one of which is connected with a source of electricity, and if a piece of uranium is brought near, there is established between the two conductors a continuous current of electricity. Such are the principal facts that I had observed.

In 1897 Lord Kelvin and Messrs. Beattie and S. de Smolan varied the conditions of the preceding experiments, and showed that the uranium radiation established between two metals in air the same equilibrium as a drop of water which united them. In I899 Mr. E. Rutherford made it clearly apparent that the conductibility set up in gases by uranium was due to a phenomenon of ionisation identical with that which, according to the experiments of Prof. J. J. Thomson, is provoked by the Röntgen rays.

In 1898 the discovery of new radiating bodies gave a new and fruitful impulse to these studies. Mme. S. Curie and M. Schmidt had recognised that thorium possesses analogous properties to those of uranium; then Mme. Curie observed that certain uranium minerals were more active than either metallic uranium or thorium. M. and Mme. Curie concluded from this that there existed other radio-active bodies, and undertook to isolate them.

I cannot analyse here the chemical part of the fine work of M. and Mme. Curie, who, working with the electrometer as the chemist works with the spectroscope, succeeded in extracting from pitch-blende two very active substances : on the one hand, a product containing bismuth and a body which they called polonium; and, on the other hand, a mixture of barium and another new substance, radium.

When they had prepared some centigrams of products the activity of which, progressively increasing, became several thousand times greater than that of uranium, $M$. and Mme. Curie were good enough to give me some milligrams, so that we could thus pursue parallel researches on the new properties.

M. and Mme. Curie recognised, among other important properties, that these bodies excite the fluorescence of the platinocyanides; that the salts of radium are spontaneously luminous; and further, that all bodies receiving the new radiation become radio-active in their turn, but that they gradually lose this property with time. They observed also, as well as Giesel, who prepared mixtures analogous, but less active, to those of M. and Mme. Curie, that the salts of radium increase spontaneously in activity for some time after their preparation, whilst the activity of polonium salts diminishes. The new radiation produces various chemical actions, alteration of the platinocyanides, violet coloration of glass, production of ozone, \&c.

For my part, I have observed that the polonium radiation does not traverse even black paper; it is much less penetrating than that of radium, which, moreover, provokes in bodies which it encounters a secondary penetrating radiation which marks a photographic plate in the immediate neighbourhood of the points struck. I have been able to establish also that the intensity of the phosphorescence excited by radium varies as the inverse square of the distance of the excited body from the radiating source ; that the unequal weakening produced by a given screen on the phosphorescence of different substances furnishes a new proof of the heterogeneity of the exciting radiation; and, lastly, that the radiation of radium restores the property of becoming phosphorescent by heat to such bodies as fluor spar, leucophane, \&c., which had lost this property by a preliminary heating.

I would here point out the very interestung researches of M. and Mme. Curie, M. Owens, and of Mr. E. Rutherford upon the penetrating rays of thorium. Mr. E. Rutherford has found that thorium compounds emit, in addition to this ordinary radiation, a very penetrating "emanation" that produces temporary radio-activity in substances in the neighbourhood, if the bodies are all uncharged. With charged conductors the radio-activity is produced on the negatively charged body. The radioactivity can thus be concentrated on the surface, of thin wires, and removed by hydrochloric and sulphuric acids, whose solution, when evaporated, leaves the active portion behind. Thorium may perhaps owe a part of its properties to a new element, actinium, discovered in 1900 by M. Debierne, and which is as active as radium.

At the end of 1899 several observers discovered, nearly simultaneously, that the rays from certain radiating substances were deviated by a magnetic field. This was first shown by M. Giesel with preparations of polonium and radium, then by MM. S. Meyer and E. v. Șchweidler, who some days later showed the same thing with preparations made by M. Giesel, and then, a little later, without having any knowledge of these observations, I recognised that the radium radiation concentrated itself upon the poles of a non-uniform magnetic field, whilst the radiation of polonium prepared by $M$. and Mme. Curie is not deviated. The preparation of polonium of M. Giesel was, then, not the same substance as that of M. and Mme. Curie.

It resulted from these observations that there exists two kinds of radiations, one not capable of deviation and of which the nature is still unknown, the other capable of deviation, which later experiments have identified with the kathode rays. Somewhat later, M. and Mme. Curie recognised that both these rays coexisted in the radium radiation. The non-deviable rays are much less penetrating than the deviable rays ; the polonium radiation is limited in air to a kind of sheath of some centimetres in thickness. I might add that recently M. Villard has proved the existence in the radium radiation of very penetrating rays which are not capable of deviation. M. Debierne has recognised that actinium emits some deviable rays.

I have devoted numerous experiments to the study of the deviation of radium in the magnetic field. This radiation is dispersed by the field into rays of different natures, like as light is dispersed by a prism. For each simple radiation, the trajectory in a plane perpendicular to a uniform field is a circumference of radius $R$, which brings back the radiation to the point of departure. If the radiation makes at the origin an angle $a$ with the axis of the field, the trajectory is a helix rolled on a cylinder parallel to the field and of radius $\mathrm{R} \sin a$. The product $\mathrm{H} \mu$ of the component of the field normal to the displacement at a point, by the radius of curvature of the trajectory in this point is constant, and may serve to characterise each simple radiation.

To obtain a beam in which each simple radiation would have a unique trajectory, a radiant source may be taken of very small diameter, the radiation being received after traversing a narrow gap in a sheet of lead.

No. 1634 , vol. 63] 
It is shown by experiment that it is sufficient to arrange between the polar pieces of an electromagnet a hori. zontal photographic plate upon which is placed, in the centre of a little leaden dish, the radiating source of very small diameter. The rays emanating normally to the plate and brought back orthogronally on it are the most efficarious; the impression, large and diffuse, is thrown on one side of the field, and constitutes a sort of spectrum which is sufficiently pure. If one works in the dark, and places on the plotographic plate bands of various substances, aluminium leaf, copper and platinum foil, $\&$ c., it is seen that under the screens the impression of the deviated rays is limited by elliptic arcs, distinguished from each other. Each screen arrests different radiations, the most deviated being the most absorbable. The dimensions of the elliptic arcs are in accordance with theory. The absorption is the same in air and in an absolute vacuum. These experiments constitute a sort of magnetic spectrum analysis of the deviable radiation.

The identification of this radiation with the kathode rays requires two other verifications--the demonstration of the existence of a transport of electric charges and that of a deviation in an electrostatic field. M. and Mine. Curie have made the first verification, and I lave realised the second. M. and .Mme. Curie placed a screen, isolated from all contact with the air, in connection with an electrometer, and observed that the radium radiation chárged this screen negatively, whilst the source itselt, if it is properly isolated, is charged positively. The current for each square centime:er of radiating surface was about $4 \cdot 10^{-13}$ electromagnetic C.G.S. units.

For my part, I showed that in an electric field the radiation of radium undergoes a parabolic inflection in the contrary sense to the field, as would be the case with a flux of negatively charged particles. The comparison of the electrostatic and magnetic deviations allows of the determination, like that of Prof. J. J. Thomson for the kathode rays, of the velocity of the particles. For the particular radiations defined by $\mathrm{H} \rho=\mathrm{I}(600$, the velocity has been found equal to $1.6 \times 10^{10}$ about one-half of that of light. The ratio of the material masses carried off to the charges which they transport has been found equal to $10^{-7}$, a number identical with that corresponding to the kathode rays. From these numbers, and that which results from the experiment of $M$. and $M m e$. Curie, it follows that for each square centimetre of surface of the radiating substance studied there escapes a flux of material which would amount to a loss of about one milligramme in one thousand million years. If the material emission, which appears to be of the same order as the evaporation of certain scented substances, is the first cause of the observed phenomena, there would be no contradiction betiveen the apparent absence of any source of energy and the continuous emission of this energy.

The most deviable portions of the radium radiation pass easily through all bodies when they are very near the source, but are stopped when these bodies are some centimetres distant. I have further recognised that, after having traversed a screen, the radiation possesses the same magnetic deviability.

I can only give here the physical properties of radioactivity. One of the most important applications has been the discovery, by $M$. and Mme. Curie, of new chemical elements. Radium has a high atomic weight, and a characteristic spectrum observed by $M$. Demarçay. Polonium, according to recent researches, has a spectrum in the ultra-violet. These bodies possess, then, the characters of simple substances.

Recent studies on induced radio-activity appear to open still new horizons. It has been mentioned already that a body becomes temporarily active when it receives the radiation of an active body. $M$. and Mme. Curie NO. 1634 , vOL. 63$]$ and $M$. Giesel have recognised that the induced activity thus provoked was much greater if the body was mixed in solution with an active salt and then afterwards separ. ated by precipitation. In thus rendering barium active with actinium, M. Debierne has recognised that the active barium behaves as a different body from ordinary barium, that it could be separated chemically and concentrated. Active barium thus resembles radium. It differs from it by the absence of a peculiar emission spectrum and by the fact that its activity weakens with time. I would add that recently Sir W. Crookes, who has made numerous experiments by the photographic method, announced that he had prepared uranium that was almost inactive. According to these experiments, as well as those of M. Debierne, M. Giesel and myself, it would appear to follow that the activity of uranium is due in great part, if not altogether, to a small quantity of actinium or of another radio-active body.

These facts, although increasing the complexity of radio-activity from the chemical point of view, do not, however, remove from it its value; it can be remarked that if the existence of uranium as a simple body had been unknown up to the present, its radiant properties would have permitted of its isolation, even though they are not inseparable from its existence.

This short account shows that a new order of phenomena has arisen from the study of a new property of matter-radio-activity.

HENRI BECQLEREL.

\section{PROGRESS OF THE MAGNETIC SURVEY OF THE UNITED STATES.}

$\mathrm{THE}$ special division of the United States Coast and Geodetic Survey devoted to the magnetic survey of the United States, and countries under its jurisdiction, was created by the late superintendent, Dr. H. S. Pritchett, now president of the Massachusetts Institute of Technology, on July I, 1899 ; and Dr. L. A. Bauer was put in charge of the division. Since that date magnetic observations-namely, declination, dip and intensity of magnetic force, have been made up to December 3 I, I900, at about 500 stations distributed over the United States, Alaska and the Hawaiian Islands. At most of the stations permanent marks have been established for the use of the surveyor. Special consideration has also been given to the needs of the mariner, especially in Alaskan waters, where occur places of pronounced local attraction affecting the compasses on board ship all the way from 4 of a point to 4 points.

Special stations, known as "repeat" or "secular variation" stations, have also been established in different parts of the United States. At these, observations will be repeated at stated intervals in order to determine the amount of secular change in the magnetic elements. It is the endeavour, whenever possible, to establish such stations in the vicinities of colleges and universities, as experience has shown that on college grounds there is hope for a permanency of station for a fairly long interval.

Of special State surveys mention may be made first of the completion of the magnetic survey of Maryland, which was undertaken primarily by the Maryland Geological Survey and assistance rendered by this I3ureau; second, the completion of the magnetic survey of North Carolina, conducted under the joint auspices of this Bureau and the North Carolina (ieological Survey; third, the completion of the magnetic survey of West Virginia ; and fourth, the completion of the magnetic survey of Iowa.

Fair progress has also been made in the establishment of the magnetic base stations, where the countless variations of the earth's magnetism will be recorded photo: graphically. 'Ihus, a temporary magnetic observatory 